\title{
IMPACT OF ORGANIZATIONAL SOCIALIZATION TOWARDS EMPLOYEES' SOCIAL ADAPTATION
}

\author{
UDC: 331.104 .2 \\ 331.105.2-057.16:316.614 \\ Review Scientific Paper
}

\author{
Biljana RATKOVIĆ NJEGOVAN ${ }^{1}$, Branislava KOSTIĆ \\ ${ }^{1}$ University of Novi Sad, Faculty of Technical sciences, Department for industrial engineering and management \\ 21000 Novi Sad, Trg Dositeja Obradovića 6, Republic of Serbia. E-mail: njegovan@uns.ac.rs \\ ${ }^{2}$ University of Novi Sad, Faculty of Technical sciences, Department for industrial engineering and management \\ 21000 Novi Sad, Trg Dositeja Obradovića 6, Republic of Serbia
}

Paper received: 15.03.2014.; Paper accepted: 27.05.2014.

\begin{abstract}
The paper discusses the importance of organizational socialization as a process of gaining knowledge on the organizational success of employees' social adaptation and encouraging their social competence. Organizational socialization as a scientific discipline as well as practically oriented adjustment activity towards employees' working environment has developed methodology and tactics of socio-cognitive, behavioural and motivational encouragement of employees to the acceptance of organizational culture. It is assumed that in the process of organizational socialization, in addition to professional and organizational adaptation, the focus is on the development of employees' social competences. Although within the evaluated performance appraisal of social competence is only estimated, and also neglected in the overall assessment of employees' work performance, organizational climate for good social skills is of great importance due to the fact that enhanced social and interpersonal communication and interaction can increase operating synergies and contribute to better business results. Although social skills are an important element of human capital, they are still insufficiently recognized as a form of intangible resources that participate in the long-term value creation. The deficit in this area can lead to the problems in performance of human relations at the workplace.
\end{abstract}

Keywords: organizational socialization, social competence, organizational socialization tactics, the tactic of investiture, employees.

\section{INTRODUCTION}

The entry of new employees into the organization represents a significant change for both the new employee and the organization. Given that the changes mainly encounter with the unknown, it causes some resistance, especially if the organization leaves a new employee to individually cope with the new work environment based on the "swim or sink." Due to minimized resistances, reduced uncertainty, and easier joining the organization and workers' training to do their job better, many organizations implement programs of organizational socialization, as well as a wide network of support for new employees in getting used to the new working environment. Success of organizational socialization will depend on the openness of communication of superiors and subordinates, facilitating the interaction by superiors and colleagues, understanding the role (function) and organizational commitment, and especially the tactics of organizational socialization. But there is a quest whether the process of organizational socialization can significantly change some individual characteristics and attitudes of the new employee. Taking into account the objectives, in particular the different tactics of organizational socialization, it is possible to influence already formed attitudes, habits, and adopted values, and achieve new modes of behaviour that are in the interest of both companies and their employees (Ratković Njegovan and Vukadinović, 2011). The concept of organizational socialization is founded as mutual perspectives of newly arrived workers and organizations; as a dynamic process of mutual 
adaptation, therefore, as the interaction of socialization and individualization. It is assumed that, with the necessary knowledge and professional competence of newly employed workers, the organization considers its desirable qualities and social skills. Social competence means an individual capacity to function within the context of culturally integrated patterns of human behaviour defined by the group; provision of social acceptance on one side and social transition on the other. The methods and tactics of organizational socialization, which the organization will use to encourage social competencies and skills as an important factor of self-efficacy, should be oriented to social tactics, ie . tactic of giving (authority), because they achieve positive feedback , mutual trust and promote employee's individual identity.

\section{ORGANIZATIONAL SOCIALIZATION AS A PROCESS OF ALIGNING INDIVIDUAL AND ORGANIZATIONAL INTERESTS}

Organizational socialization is a dynamic process of acquiring organizational knowledge and organizational skills; this is a process by which people learn the norms and roles necessary to function within a group or organization. In fact, socialization in the organization makes a constant learning process, a never ending, constantly renewing process of relating reflections and actions, where knowledge is being created through the transformation of experience. It is a process by which an individual acquires the social knowledge and skills necessary to assume an organizational role, and which unfolds through pre-entry, confrontation and transformation stages (Van Maanen and Schein, 1979). Successful organizational socialization enables new employees to be easier and better fit in the organization and adapt in professional and social terms. That success will have a positive effect on work motivation, job satisfaction, work efficiency, reduction of uncertainty regarding the majority of business performances and hence on the projection of long-run individual commitment to the organization. Successful organizational socialization is primarily reflected in the alignment of personal and organizational interests. This alignment is primarily dependent on the existing harmony between the individual and his job, i.e. the harmony between the individual's knowledge, skills and social abilities on one hand and his job demands, as well as the harmony between the individual and his organization. Organizational socialization is the basic form of creating organizational knowledge, proving to be a good way of managing organizational behavior.

\section{Organizational socialization as a scientific discipline and practice-oriented activity}

The concept of organizational socialization has already been foreshadowed in the fact that organizational culture, apart from the aspect of management theory, can be viewed based on a "softer" anthropological-sociological approach (Pettigrew, 1979), which takes into account the importance of subjective view of organizational life (Turner, 1986; Martin et al., 1983; Smircich, 1983). As assumed by this approach, the process of organizational socialization involves the process of individuation, meaning that the individual is able to overcome the existing social realities and be changed in accordance to his own needs and values. It could be said that the idea of organizational socialization is aimed at transforming the unilateral process of adaptation of man to the organization, critically elaborated by Whyte (1956) as "organization man", to a dynamic process of cognitive, affective and symbolic adaptation of individuals to the work and organizational environment. On the other hand, organizational socialization, as a set of the individual's cognitive and symbolic adaptation mechanisms, triggers the organization's functional and reproductive capabilities. In this regard, Feldman (1981) states that the process of socialization leads to three fundamental types of changes: adopting a set of acceptable models of behavior, developing work skills and the ability of adapting to the norms and values of the work group.

During the last three decades, organizational socialization as a scientific discipline and a practically oriented activity aimed at adapting the employees to the working environment has developed methods and approaches of social, cognitive, behavioral and motivational encouragement of employees to the acceptance of organizational culture. Therefore, the field of organizational socialization became extremely diverse and includes a variety of areas, such as personality, identity, learning (particularly of social skills), socialization and re-socialization. It also covers the issues of emotion, motivation, attitudes, behaviors, job roles and values, including the processes of identification, transfer of loyalty, cultural changes, etc. In the context of interactional perspective, the level of the individual's professional adaptation, self-confidence and the 
self-assessment of the own efficacy in initiating motivational and cognitive resources needed to perform specific tasks in the given context are regarded as desirable outcomes of organizational socialization (Bandura, 1997; Luthans, 2002).

\section{Organizational socialization and social adaptation of new employees}

Instead of involving merely the cognitive, symbolic and professional adaptation to the new working environment, the process of organizational socialization also assumes processes of social adjustment and acceptance by others. Despite the fact that social competences in the framework of evaluating the employees' job performance are rated based only on estimates while not accounted for in the overall job performance, they are of great importance for a good organizational climate. Also, by contributing to the improvement of social and interpersonal communication and interaction, they also improve the levels of synergy and enable better business results to be achieved. Social skills, despite the fact that they are important elements of human capital, are still underrated as a form of intangible resources influencing value creation in the long run. The deficit in this area can lead to performance-related problems regarding human relations at the workplace.

This domain of business relationships has been particularly topical in crisis situations in the company, e.g. in situations of transition between the so-called "normal" and "exceptional" situations (Lalonde, 2010). This also includes situations that are characterized by job-related general uncertainty or ambiguity, such as lack of understanding of formal or informal responsibilities, ambiguities regarding roles, uncertainty regarding job retention and the like. In addition, employers are increasingly looking for workers that possess competences and skills that go beyond formal education in addition to academic, professional and business competences and technical skills and experience. These are the so-called soft skills necessary for obtaining and keeping jobs, good cooperation, teamwork, communication; they are hallmarks of personal integrity and mutual respect. Thus, here we are speaking of personal adaptive skills, of which social competences, in all their aspects of complexity and numerous varieties of manifestation are of great importance for individual positioning in any organizational environment.

\section{SOCIAL COMPETENCES AS DESIRABLE EMPLOYEE TRAITS}

As shown by business practice, social competences belong to the group of increasingly desirable employee traits. This fact is best reflected in job announcements, where, in addition to professional skills, social skills making the employees effective in different social situations are also often required. In this sense, Boyatzis (1982) developed the concept of 'competency-based' approach to human resource management. It has become integral during the last thirty years, with 'competency' encompassing the knowledge, skills, abilities, traits and behaviors that allow an individual to perform a task within a specific function or job.

Exploring employee competences important for enhancing individual skills (Spencer and Spencer, 1993) and essential for the establishment of competency-based human resource management, Vathanophas and Thai-ngam (2007) stated the following: developing others, organizational awareness, achievement orientation, professional expertise, self-improvement, team leadership, interpersonal understanding, relationship building and coordination, organizational commitment, initiative, flex confidence, communication and influence, IT and computer literacy, serviceminded, analytical thinking, integrity, concern for order, quality, and accuracy, information seeking, self -control, conceptual thinking, and English skills respectively. According to Carneveale et al. (1989), desirable social skills of employees include positive attitude, self-esteem, ability to work with others, conflict resolution, as well as many other forms of using personal relationships based on which social inclusion and acceptance could be achieved.

The concept of social competences is a complex and multidimensional relational concept, given that it includes social, emotional, cognitive, behavioral and axiological dimensions. Therefore, the definition of this phenomenon needs to be approached from various perspectives. Social competences are commonly related to social skills, such as solving problems, taking perspectives and personal perception (Sarason, 1981). Although social competences and social skills are closely related concepts, some differences between them still exist: social skills are defined as a set of mutually related, goal-oriented social behaviors, which can be learned and controlled, while social competences are defined as ways to which an individual uses his skills in a social environment. 


\section{Views on the contents of social competences}

In defining social competences, authors are mainly focused on studying individuals and the sociopsychological resources they are using for adaptive purposes, or on the aspect of integrating the behavior, i.e. aspects of their integrative capacity. Social competences are also defined as personality traits, which are manifested in different forms, such as empathy, conscientiousness, ability to cooperate, tolerance (Sarason, 1981). Argyle (1994) and Tajfel (1981) view social competences as a dynamic construct, which includes the ability to adapt and interact in a particular social situation. In psychology, social competences are used to assess personality traits, such as willingness to cooperate, conscientiousness and extraversion, self-esteem, self-efficacy and locus of control.

Whyte (1959), for example, views social competences as the capacity of the body to communicate with their environment in an effective manner, while Goldfried and d'Zurilla (1969) emphasize the importance of efficiency and adequacy in responding to various problematic situations. When it comes to social competences, Rubin and Rose-Krasnor (1992) and O'Malley (1977) relate personal and social factors, viewing them as abilities to achieve personal goals in social interaction, while keeping positive relationships with others, i.e. "the ability to interact with others and to be competent in doing so has been ranked as one of the most important skills that we can have" (Hartup, 1991).

In some definitions of social competences (Foster and Ritchey, 1979, Anderson and Messick, 1974), the emphasis is on the outcomes of socially desirable behavior in terms of effectiveness in achieving social goals, such as making friends, popularity, success in social interactions with others, etc. On the other hand, Marlowe (1986) believes that the essence of social competences is in the orientation toward the others and the ability to understand both the others' and the own feelings, thoughts and behaviors in interpersonal situations. Katz and McClellan (1997) suggest that competent individuals are those who can take advantage of incentives from the environment and achieve good development results that provide satisfactory participation in communities and the wider society. Goleman (1997) relates social competence to emotional intelligence, stating that it improves effective functioning in the social context. The European Commission (2005) identifies social competence as one of the key benchmark indicators based on which the tendencies towards prosperity and well-being in respective countries can be identified.

In the economy, especially in management, social competences are used in terms of soft skills, as personal attributes that enhance the skills of interaction, business performance and career prospects. They also include flexibility, teamwork, and motivating colleagues and clients. In this sense, the importance of soft skills may be higher than that of professional skills, given that they include skills such as communication, conflict resolution, negotiation, personal effectiveness, creative problem solving, strategic thinking, team building, etc. When it comes to organizational logic, the following three competences are commonly required: social competences (communication, teamwork, negotiation, etc.), professional competences (knowing the company's system, marketing and sales, knowing the products, etc.), and business competences (knowing the ways of organization, using information technology, etc.).

\section{TACTICS AS THE MOST INFLUENTIAL FACTOR OF ORGANIZATIONAL SOCIALIZATION}

Organizational socialization is the process through which organizational culture is perpetuated, and newcomers learn the appropriate roles and behaviors to become effective and participating members (Louis, 1980). Organizational socialization contributes to the success and enables the relations among employees to be harmonized depending on the quality of their social integration in the enterprise, and is reflected on productivity, performing the roles, building attitudes, commitment and dedication to the organization.

The top five influential factors of organizational socialization include job characteristics, defining roles, tactics of organizational socialization, previous experience, and social inclusion. Indeed, the domain of social inclusion represents an important step in building the employees' working capacity. In addition to other elements, it includes interventions in terms of respecting and encouraging the existing and development of desirable social skills. This process varies from organization to organization, and usually is the function of the content of organizational culture and the type of management in the organization. This raises the following question: what are the tactics of organizational socialization (Van 
Maanen and Schein, 1979) that may contribute to higher appreciation of social skills needed by the organization? Van Maanen and Schein (1979) conceived tactics of organizational socialization in six dimensions. Each dimension consists of a bipolar pair (continuum) due to the fact that the process of socialization unfolds between what is institutionalized and what is individualized. Institutionalized tactics provide all the important information on the organization and the role, reducing thereby the uncertainty and anxiety of new employees, which are accompanying factors when entering the organization. In contrast, individual tactics provide each employee with a unique set of learning experiences through competent mentors (agents) of socialization. When it comes to performing job tasks, the views of employees experiencing individualized tactics of socialization is far more heterogeneous than those of employees experiencing a collective socialization process. The six dimensions are the following: collective vs. individual socialization processes; formal vs. informal; sequential vs. variable; fixed vs. variable; serial vs. disjunctive; and investiture vs. divestiture.

\section{The tactics of investiture supports the employees' social competences to be manifested}

Organizations use a wide range of tactics and techniques that allow the integration of new workers and their "accommodation" in the organization. In the context of the theory provided by Van Maanen and Schein (1979), the tactics of organizational socialization involves various ways of structuring experiences transmitted by members of the organization to the newly hired workers when taking their job roles. Tactics of organizational socialization can be chosen in a conscious and planned manner by the company management, e.g. requiring all new employees to attend formal sessions, training meetings or orientation programs before they take their specific job roles. These are formal forms of socialization (orientation) and include clear, pre-defined and formalized programs and activities aimed at introducing new employees to the business, their integration into the organization and their training for doing their jobs in a successful manner. In case of socialization and orientation of managers and other professional staff, these programs have become almost inevitable.

In terms of respecting social competences in organizations, management is sometimes focused more on relationships, sometimes on skills, and sometimes on outcomes. These are contexts in which management opts for a specific tactics of organizational socialization. However, if the organization believes that it can benefit from qualities already possessed by the employees, which can be channeled to benefit the organization, in this case investiture ${ }^{1}$ can prove to be an effective tactic. This tactic of organizational socialization promotes the self-confidence of new workers, particularly with regard to the acceptance of their skills and knowledge by senior members of the organization, provides new members of the organization with support and trust (Feldman, 1976), as well as a sense of need for their skills and knowledge. If the tactic includes bestowing authority, new employees will be able to shape their identities and actively participate in the process of organizational socialization, finding their own methods for organizational adaptation, obtaining information and establishing relationships with others.

Through the tactic of investiture organizations acknowledge, accept and reinforce the positive attributes of their new members by taking into account the fact that each worker is a complex and unique personality with its own needs, values, emotions and motives (Eisenberg and Goodall, 2001). By using the investiture tactic, instead of influencing the new employee and changing the existing body of his orientation, the intention of company management is to "extract" the benefit of existing knowledge and skills of new employees. In short, the investiture tactic provides new members of the organization with positive social support that encourages a sense of competence and confidence (Feldman, 1976) and personal identity within the organization.

\section{CONCLUSION}

Social competences enable effective functioning in various social situations. In context of business organizations, it implies professional competence and understanding the job role, ability to communicate effectively, understanding themselves and the others, accepting organizational and work norms, and emotional regulation. Although social competence is largely a

\footnotetext{
${ }^{1}$ Opposite to the tactic of investiture is the tactic of deprivation (divestiture), where organizations explicitly indicate that they expect of new employees to change their existing attitudes and behaviors, and adopt new attitudes and behaviors considered desirable by the organization.
} 
consequence of socio-emotional maturity and life experience, and only partially can and learned, this paper is based on the premise that a well-conceived induction program of organizational socialization as a primary process of organizational learning can contribute to the stimulation of existing and acquisition of new social competences. They are reflected in the development of social abilities and social skills, adaptability, managing emotions in relationships, capacity of assuring and directing the others, and positive responses to others.

Within the concept of organizational socialization through the use of socialization tactics organizations are enabled to actively embed new employees, while new employees are enabled to play a proactive role in their socialization. The investiture tactic proved to influence constructively on-the-job embeddedness. Although this tactic increases uncertainty regarding the requirements of the role (for example, role replication vs. role innovation), it facilitates and encourages organizational learning. If the organization in the process of organizational socialization opts for integrating new employees using primarily the investiture tactic, it is reasonable to assume that in this case, it recognizes and affirms their professional and personal identity and encourages their social interactions in the given organizational environment. Clearly, the quality of these social interactions significantly depends on individual traits which are primarily considered through the prism of social competences. Extensive research in this area has yet to confirm the importance of these relations.

\section{REFERENCES}

Anderson, S., \& Messick, S. (1974). Social competency in young children. Developmental Psychology, 10(2), 282-293.

Argyle, M. (1994). The Psychology of Interpersonal Behaviour. London: Penguin.

Bandura, A. (1997). Self-efficacy: The exercise of control. New York, NY: W. H. Freeman and Company.

Boyatzis, R. (1982). The Competent Manager: A Model for Effective Performance. New York: John Wiley \& Sons.

Carneveale, A. P., Gainer, L. J., \& Meltzer, A. (1989). Workplace Basics: The Skills Employers Want: American Society for Training and Development and U.S. Dept. of Labor.

Eisenberg, E. M., \& Goodall, H. L. (2001). Organizational communication: Balancing creativity and constraint (3rd ed.). Boston, MA: Bedford / St. Martina.
European Commission. (2005) Working together for growth and jobs: A new start for the Lisbon Strategy. Communication 33. Brussels.

Feldman, D. C. (1976). A practical program for employee socialization. Organizational Dynamics, 5(Autumn), 64-80.

Feldman, D. C. (1981). The multiple socialization of organization members. Academy of Management Review, 6(2), 309-318.

Foster, S. L., \& Ritchey, W. L. (1979). Issues in the assessment of social competence in children. Journal of Applied Behavior Analysis, 12(4), 625638.

Goldfried, M. R., \& D'Zurilla, T. J. (1969). A behavioral-analytic model for assessing competence. In C. D. Spielberger (Ed.), Current topics in clinical and community psychology (Vol. I, pp. 151-196). New York: Academic Press.

Goleman, D. (1997). Emocionalna inteligencija. Beograd: Geopolitika.

Hartup, W. (1991). Having friends, making friends, and keeping friends: Relationships as educational contexts. Early report. Minnesapolis, MN: Centre for Early Education and Decevelopment.

Katz, L. G., \& McClellan, D. E. (1997). Fostering children's social competence: The teacher's role. Washington, DC: National Association for the Education of Young Children.

Lalonde, C. (2010). Organisational socialisation in a crisis context. Disasters, 34(2), 360-379.

Louis, M. R. (1980). Surprise and sense making: What newcomers experience in entering unfamiliar organizational settings. Administrative Science Quarterly, 25(2), 226-251.

Luthans, F. (2002). Positive organizational behavior. Developing and managing psychological strengths. Academy of Management Executive, 16(1), 57-72.

Marlowe, H. A. (1986). Social intelligence: Evidence for multidimensionality and construct independence. Journal of Educational Psychology, 78(1), 52-58.

Martin, J., Feldman, M. S., Hatch, M. J., \& Sitkin, S. B. (1983). The uniqueness paradox in organizational stories. Administrative Science Quarterly, 28(3), 438-453.

O’Malley, J. M. (1977). Research perspective on social competence. Merrill-Palmer Quarterly, 23(1), 2944.

Pettigrew, A. M. (1979). On Studying Organizational Cultures. Administrative Science Quarterly, 24(4), 570-581.

Ratković Njegovan, B., \& Vukadinović, M. (2011). Sadržaj i efekti organizacione socijalizacije u poslovnim integracijama. Škola biznisa, 3(2011), 102-115.

Rubin, K. H., \& Rose-Krasnor, L. (1992). Interpersonal problem solving. In V. B. Van Hasselt \& M. Hersen (Eds.), Handbook of social development (pp. 283323). New York: Plenum.

Sarason, B. R. (1981). The dimensions of social competence: Contributions from a variety of research areas. In J. D. Wine \& M. D. Smye (Eds.), Social competence (pp. 100-122). New York: 
Guilford Press.

Smircich, L. (1983). Concepts of culture and organizational analysis. Administrative Science Quarterly, 28(3), 339-358.

Spencer, L., \& Spencer, S. (1993). Competence at Work: Models for Superior Performance. New York: John Wiley \& Sons, Inc.

Tajfel, H. (1981). Human groups and social categories. Cambridge: Cambridge University Press.

Turner, B. A. (1986). Sociological aspects of organizational symbolism. Organizational Studies,
$7(2), 101-115$.

Van Maanen, J., \& Schein, E. H. (1979). Towards a theory of organizational socialization. In B. M. Staw (Ed.), Research in Organizational Behavior (Vol. I, pp. 209-264). Greenwich, CT: JAI Press.

Vathanophas, V., \& Thai-ngam, J. (2007). Competency Requirements for Effective Job Performance in The Thai Public Sector. Contemporary Management Research, 3(1), 45-70.

Whyte, W. H. (1956). The Organization Man. New York: Simon \& Schuster. 